\title{
An initial response of magnetic fields at geosynchronous orbit to Pi 2 onset as observed from the dip-equator
}

\author{
O. Saka ${ }^{1}$, H. Akaki ${ }^{2}$, O. Watanabe ${ }^{2}$, M. Shinohara ${ }^{2}$, D. N. Baker ${ }^{3}$ \\ ${ }^{1}$ Department of Physics, Kurume National College of Technology, 1232-Komorino, Kurume 830, Japan Fax: +81942 359307 \\ 2 Department of Earth and Planetary Sciences, Kyushu University, Fukuoka, Japan \\ ${ }^{3}$ Laboratory for Atmospheric and Space Physics, University of Colorado, Boulder, Colorado, USA
}

Received: 30 June 1997 / Revised: 13 November 1997 / Accepted: 24 November 1997

\begin{abstract}
Fluxgate magnetometer data recorded at the dip-equator (Huancayo, Peru; $1.44^{\circ} \mathrm{N}, 355.9^{\circ}$ in geomagnetic coordinates; $12.1^{\circ} \mathrm{S}, 75.2^{\circ} \mathrm{W}$ in geographic coordinates; $L=1.00$ ) with higher accuracy of timing $(0.1 \mathrm{~s})$ and amplitude resolution $(0.01 \mathrm{nT})$ were utilized to survey an onset of Pi 2 pulsations in the midnight sector (2100-0100 LT) during PROMIS (Polar Region and Outer Magnetosphere International Study) periods (1 March-20 June, 1986). It is found that changing field line magnitude and vector as observed by magnetometer on board the synchronous satellites in the midnight sector often takes place simultaneously with the onset of Pi 2 pulsations at the dip-equator. The field disturbances that follow thereafter tend to last for some time both at the geosynchronous altitudes and the dip-equator. In this report, we examine the initial response of the field lines in space, and attempt to classify how the field line vector changed in the meridional plane.
\end{abstract}

Key words. Magnetospheric physics - Magnetospheric configuration and dynamics MHD waves and instabilities · Plasmasphere

\section{Introduction}

Pi 2 magnetic pulsations (damped oscillations with periods of 40-150 s) associated with substorm expansion onset have been widely investigated, and basic morphological pictures were established in the 1960s and 1970s (see Saito, 1969; Jacobs, 1970; Orr, 1973; Lanzerotti and Fukunishi, 1974; Southwood and Stuart, 1980; McPherron, 1980; Pashin et al., 1982; Sakurai and McPherron, 1983; Samson and Rostoker, 1983; Baumjohann and

Correspondence to: O. Saka
Glassmeier, 1984). Recently, low-energy particle flux enhancements at geosynchronous altitudes have been found to be correlated with the occurrence of Pi 2 events at a very high significance level. The correlation indicates that hot plasmas are injected into the inner magnetosphere at the Pi 2 onset (Yeoman et al., 1994; Saka et al., 1996a, 1997). Magnetic field data in the nightside sector of the magnetosphere have been studied to clarify how the field line disturbances correlate with ground $\mathrm{Pi} 2$ events. At geosynchronous altitudes, the azimuthally polarized transverse waves were often identified in association with an azimuthal gradient of the plasma pressures caused by particle injection in the nightside sector (Saka et al., 1996b, c). At $L=8-9$, standing field line oscillations are identified at substorm onset (Takahashi et al., 1988). These results may imply the existence of a local gradient of the plasma pressures in space in association with the Pi 2 onset. Indeed, Saka et al. (1996c) showed that the relaxation of the pressure gradient as a result of the particle loss from the midnight sector results in the cesation of the wave activities.

In this report, we look at magnetometer data in the night-time sector at both the dip-equator (Huancayo, Peru) and geosynchronous altitudes at a close meridian to survey field changes in space that occur at Pi 2 onset. Instead of the wave form comparison of the event, an initial change of the magnetic fields at geosynchronous altitudes was investigated. The initial response will be discussed with respect to the particle injections at Pi 2 onset.

\section{Ground-satellite correlation}

\subsection{Individual events}

The magnetic field variations measured by the fluxgate magnetometer on board the geosynchronous satellite GOES $5\left(75^{\circ} \mathrm{W}\right.$ in the geographic coordinates) were investigated during ground $\mathrm{Pi} 2$ events which were monitored by a magnetometer in the same LT sector at Huancayo, Peru $\left(1.44^{\circ} \mathrm{N}, 355.9^{\circ}\right.$ in geomagnetic coor- 
dinates; $12.1^{\circ} \mathrm{S}, 75.2^{\circ} \mathrm{W}$ in geographic coordinates; $L=1.00$ ) during the PROMIS (Polar Region and Outer Magnetosphere International Study) period (1 March-20 June, 1986). Hereafter, the geographic coordinates were used. Before proceeding to the statistical study, we briefly describe the background signatures of particle flux (electron, $30-300 \mathrm{keV}$; proton, 145$560 \mathrm{keV}$ ) and magnetic field variations during $\mathrm{Pi} 2$ onsets as observed by geosynchronous satellites, 1982019, 1984-129, 1984-037 and GOES 5. Figure 1 describes, from top to bottom, electron flux variations from the postmidnight (1982-019) to the morning (1984-037) sectors, field line changes at GOES 5 (3 h behind the local time of 1982-019) and dynamic power spectra of the $H$ component of the ground station (Huancayo). The LT of the GOES 5-Huancayo pair is UT -5 h. For this interval, Pi 2 events are demonstrated as a discrete enhancement of the spectral power of the $H$ component in the frequency range below $30 \mathrm{mHz}$, and are marked by vertical bars.

An obvious correlation with the electron flux enhancement can be seen for the last Pi 2 event at 0516 UT. In addition, field line reconfigurations in space were observed in association with this Pi 2 event, as shown in the middle panel. The coordinates used for the satellite data are spherical representation in the dipole coordinates $H, V, D(H$ is along the dipole axis, $V$ is outward and $D$ is azimuthally eastward). $\theta$ is the field line inclination measured positive upwards from the equatorial plane ( $H-V$ plane) and $\phi$ is a rotation of the field line vector in the equatorial plane measured positive counterclockwise from the $V$-axis. In the time-period shown, the reconfigurations occurred in such a way that the field magnitude increased, field line inclination $(\theta)$ increased, and the field line in the equatorial plane $(\phi)$ deflected westwards. Looking at the electron flux data in the top panel, the field reconfigurations seem to occur about $12 \mathrm{~min}$ before the flux enhancement at 1982-019 (0236-LT sector) which shows an energy dispersion. The electron population drifted further eastwards and was detected by 1984-037 with weaker amplitudes at 1018 LT. It is likely that those electrons were entrained on the field lines in the midnight sector at the time of the Pi 2 onset (e.g., Baker et al., 1978; Saka et al., 1996c).

It seems that the last $\mathrm{Pi} 2$ event accompanies all signatures in space (injection, field dipolarization and formation of field-aligned current) required for the substorm expansion onset. However, a close inspection of this event shows an oscillating response that preceded the field dipolarization. In Fig. 2, field changes during the leading edge of this event are demonstrated with an enlarged time-scale, together with the original Pi 2 wave form in the top panel. The onset timing of satellite data shown by a vertical bar can often be seen nearly simultaneously with the Pi 2 onset. The interval between the onset as observed by the geosynchronous satellite and the first amplitude peak of Pi 2 normally spans an order of one minute, as shown by the horizontal bar in the figure. We attempt to classify the field changes at the geosynchronous satellites that may occur during this 1min interval.

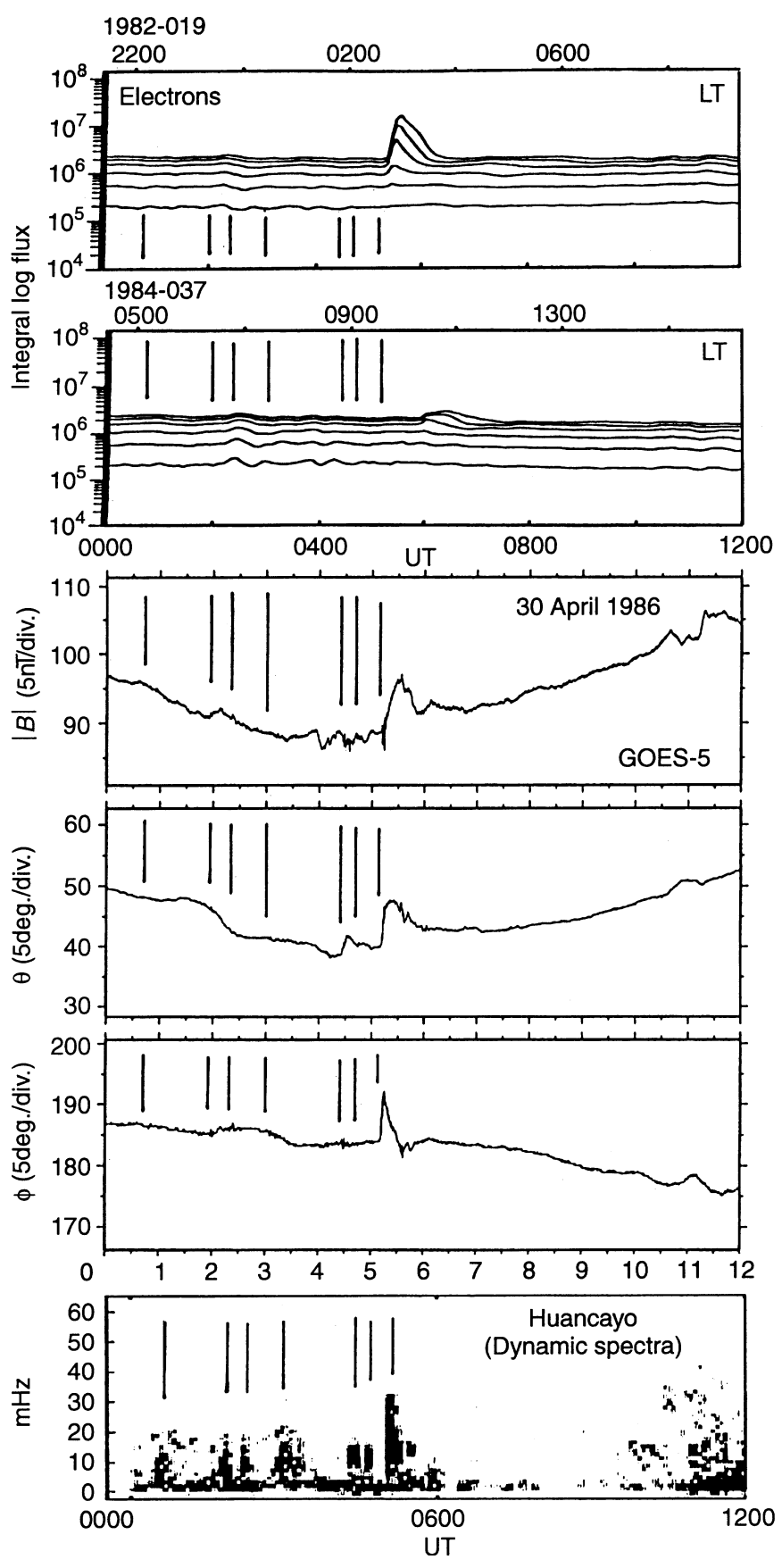

Fig 1. 12-h plot of integrated electron flux, 30-300 keV (top panel), fluxgate magnetometer (middle panel) data from geosynchronous satellites 1982-019, 1984-037 and GOES 5, and dynamic spectra of the ground magnetometer data (bottom panel) at Huancayofor 30 April 1986. The local time of the satellites 1982-019 and 1984-037 is shown in the upper part of each trace. GOES 5 and the ground station, Huancayo, are located in the same meridian, local time is UT -5 . $B$, $\theta$, and $\phi$ are field line magnitude, field line inclination and azimuth, in dipole coordinates (see text). The Pi 2 events are shown by vertical bars in the figure

Eighty-seven Pi 2 events showing a clear onset in the midnight sector (2100-0100 LT) were picked up at the dip-equator during PROMIS periods. The groundsatellite correlation may sometimes be obscure due to the overlapped disturbances in space, and it becomes 


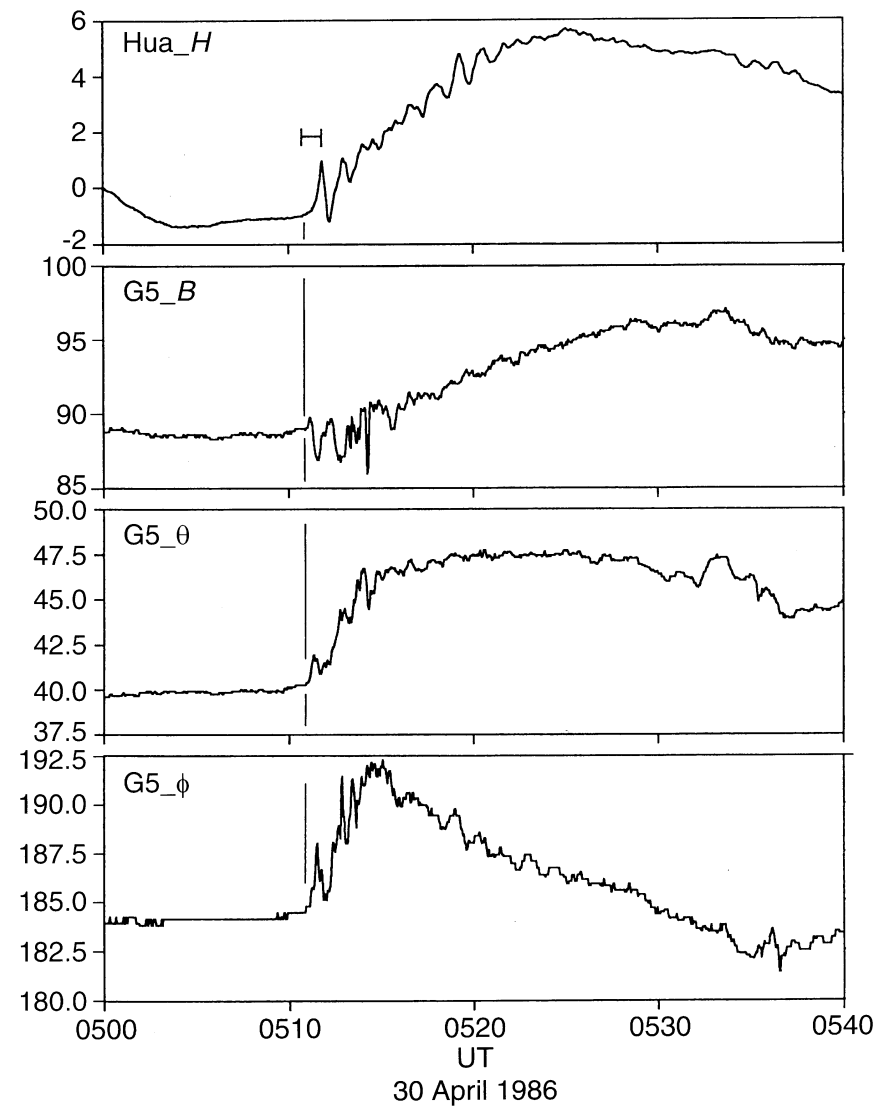

Fig 2. Enlarged plot (40-min interval) of the last Pi 2 event shown in Fig 1. Particle data are not included. The original plot of the $H$ component (positive northward) is shown instead of the power spectra. The vertical bar indicates the onset of the field line changes at the geosynchronous altitudes, which occurred in the 1-min interval (horizontal bar) of the Pi 2 onset

difficult to pick up the onset at the satellite, even if some correlation may exist. For this reason, the number of Pi 2 events being accompanied by well-defined field changes in the geosynchronous altitudes may decrease. Eventually, $59 \mathrm{Pi} 2$ events were picked up, local time distributions of which are presented in Fig. 3. To demonstrate how the satellite magnetic fields changed in the first 1 min interval, we examine five events, each of which may be classified as a typical case, as will be explained.

Event 1 (19 March 1986, Fig. 4). A 15-min plot for 0300-0315 UT is shown. The figure shows, from top to bottom, Hua_H of fluxgate magnetometer data for the $H$ component at the dip-equator (Huancayo), and $B, \theta$, $\phi, H$, and $V$ components for the satellite fluxgate magnetometer data obtained by geosynchronous satellite GOES 5. The scales shown in the vertical axis are in nT for the Hua_ $H$ and satellite $B, H$, and $V$, while $\theta$, and $\phi$ are shown in degrees. The GOES 5 satellite was at the same meridian as that of the ground station for the PROMIS periods. The field line change in space seems to begin at the time shown by the vertical bar $(0305: 42$ UT), which precedes the first amplitude peak of the Pi 2 wave form (top panel) by $42 \mathrm{~s}$.

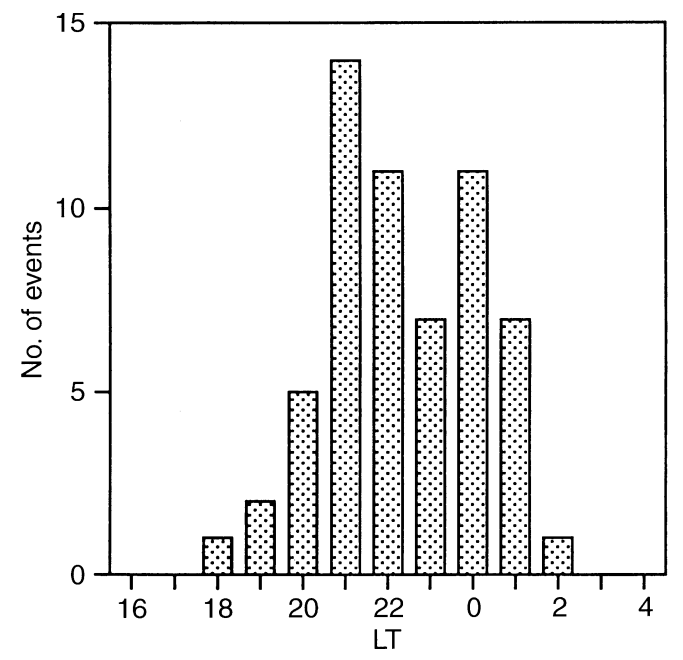

Fig 3. Local time distribution of the events in which both the field changes of the $H$ and $V$ components took place at GOES 5 or GOES 6 position at the Pi 2 onset. The satellite local time is used. The longitude of GOES 5 was the same as that of the ground station $(\mathrm{LT}=\mathrm{UT}-5)$, while for GOES 6 the longitude was $2 \mathrm{~h}$ behind the ground station

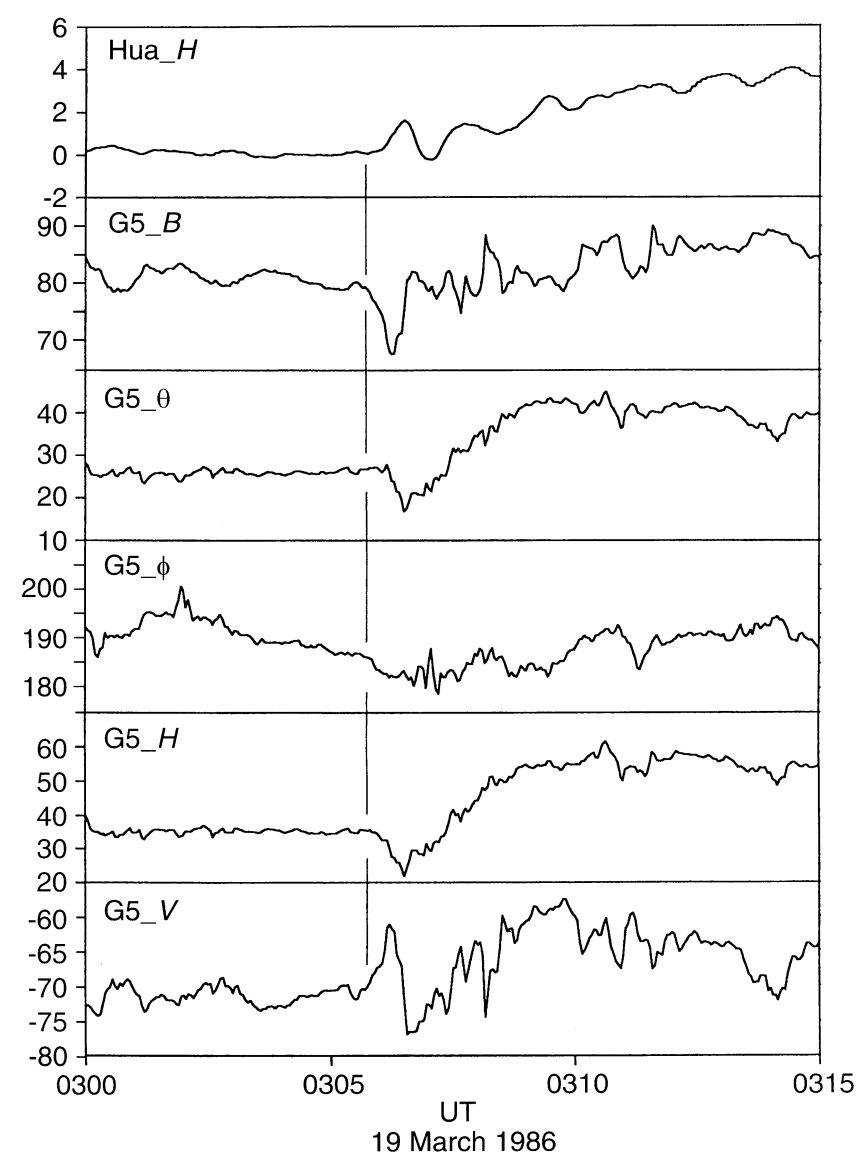

Fig 4. A $15-$ min plotout of the Pi 2 event of event 1 (19 March 1986). From top to bottom, Hua_H for the ground fluxgate data for the $H$ component at the dip-equator (Huancayo), and $B, \theta, \phi, H$ and $V$ components for the satellite fluxgate data obtained by geosynchronous satellite GOES 5. The scales shown in the vertical axis are in nT for the Hua_H and satellite $B, H$, and $V$, while $\theta$, and $\phi$ are shown in degrees. The vertical bar indicates the expected onset of the field changes at GOES 5 (see text) 
In this 1-min interval, the $B$ and $V$ completed almost one cycle, though the Pi 2 underwent only a half cycle. The $\theta$ component remained unchanged for some time, in spite of a continuing change in the $H$ (decrease), $B$ (decrease) and $V$ (increase). Generally, the responses are not simple in this way, even in this 1-min interval. Nevertheless, the initial change in space may be characterized for this event by a decrease in $H$ and an increase in $V$. These changes were accompanied by a decrease in $B$ in the background field with an inclination of $30^{\circ}$. As will be shown, the decrease in $B$ and increase in $V$ were observed very often.

Event 2 (30 April 1986, Fig. 5). The onset of the field changes at the GOES 5 was at 0425:42 UT (shown by a vertical bar). The onset occurred $1.2 \mathrm{~min}$ before the first amplitude peak of the Pi 2. The initial change in space may be characterized for this event as increases in $H$ and $V$, and a decrease in $B$ and increase in $\theta$ in the field inclination of $39^{\circ}$. Again, $B$ decreased and $V$ increased, though for this case $H$ increased.

Event 3 (30 April 1986, Fig. 6). This event was plotted previously in Figs. 1 and 2 with low time resolution. The onset in space was indicated by a vertical bar at 0516:00 UT which occurred 54 s prior to the first Pi 2 amplitude peak. The initial change in space may be characterized for this event as an increase in all the components $H, V$, $B$ and $\theta$. For the $B$ component, a small but a distinct

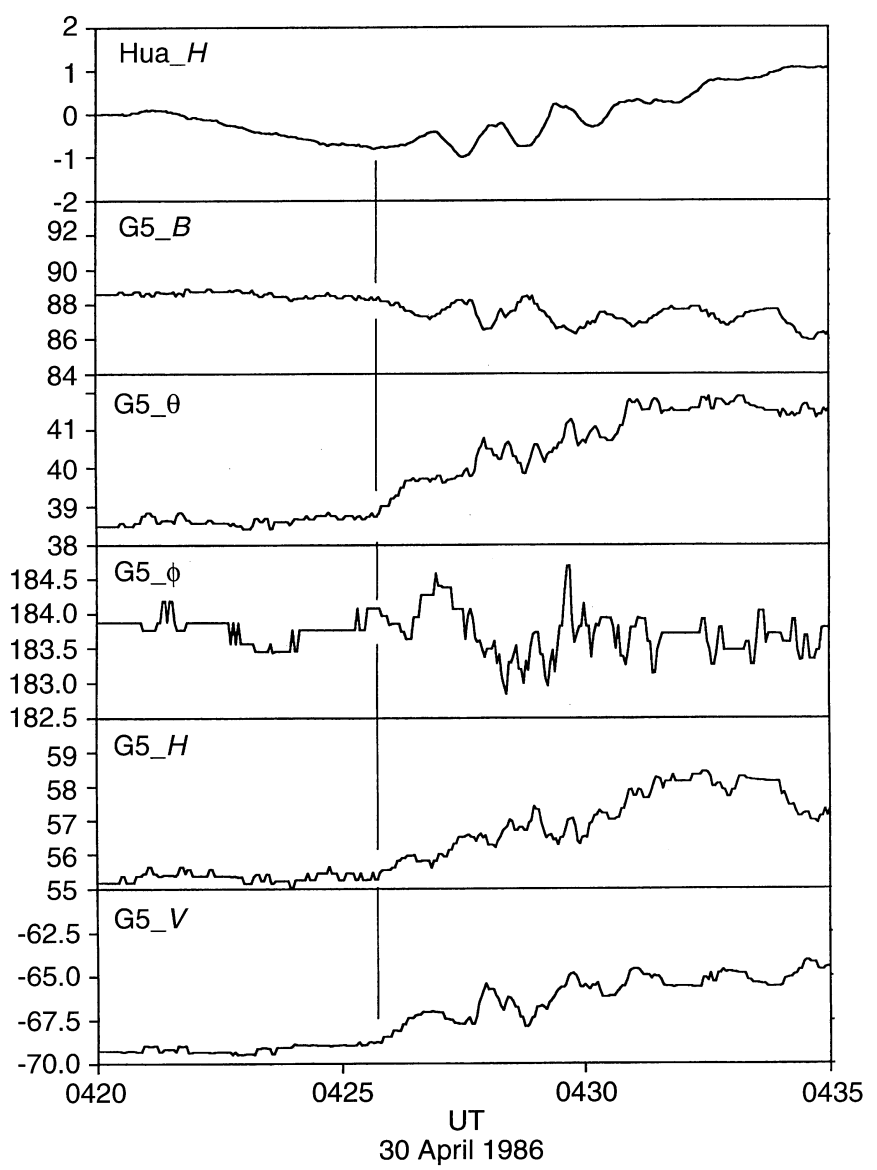

Fig 5. As Fig. 4, but for event 2 (30 April 1986)

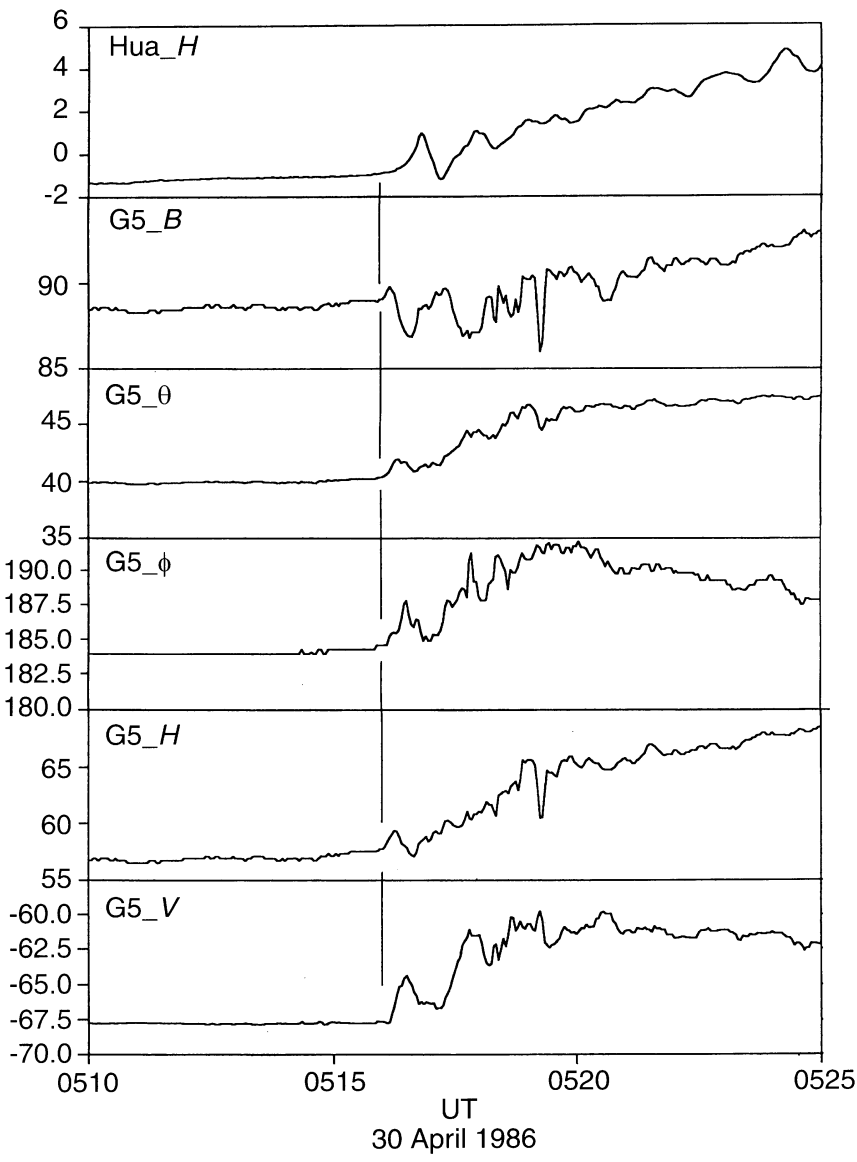

Fig 6. As Fig. 4, but for event 3 (30 April 1986)

increase was followed by a large decrease. Such an initial small increase was occasionally observed.

Event 4 (23 May 1986, Fig. 7). A sharp field change in space accompanied by a decrease in $H$, and increase in $V$ was seen to occur at 0313:30 UT, as shown by the vertical bar. These changes were accompanied by a decrease in $\mathrm{B}$ in the field inclination of $30^{\circ}$. The onset was $1.5 \mathrm{~min}$ prior to the first Pi 2 amplitude peak. Again, B decreased and V increased.

Event 5 (31 May 1986, Fig. 8). This event shows a ground-satellite correlation with the field changes recorded by GOES $6\left(107^{\circ} \mathrm{W}\right.$ in geographic coordinates, $2 \mathrm{~h}$ behind the Huancayo meridian). The field change in space occurred at 0512:54 UT, as is shown by the vertical bar. The onset was seen to occur $36 \mathrm{~s}$ prior to the first Pi 2 amplitude peak. Features to be noted for this event are a decrease in the $V$ component at the onset, which occurred infrequently. The onset occurred accompanied by an increase in B, which was also an infrequent case, in low filed inclination of $25^{\circ}$.

\subsection{Statistical results}

Of 59 Pi 2 events selected from Huancayo magnetometer data in the midnight sector, 32 showed distinct initial field changes at GOES 5, while for 27 events they appeared at GOES 6. These initial field changes were 


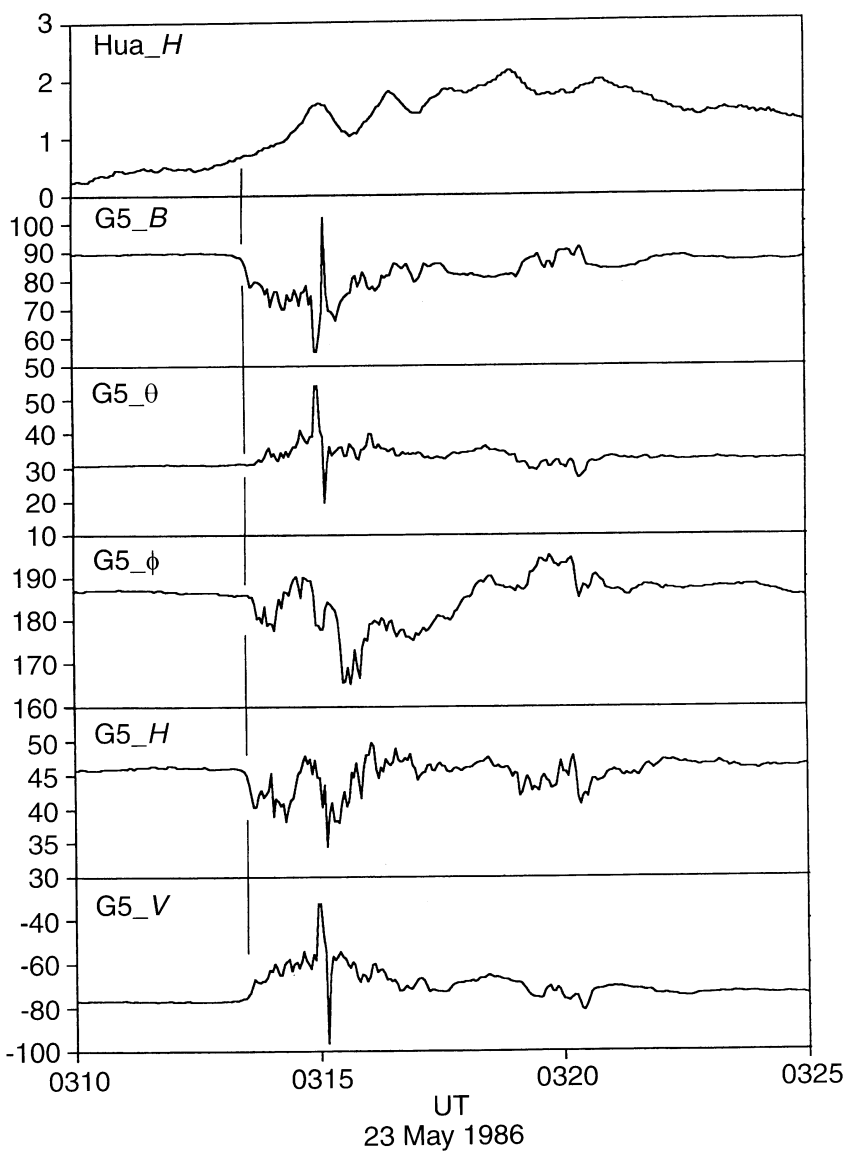

Fig 7. As Fig. 4, but for event 4 (23 May 1986)

classified separately in terms of $H-V$ components and $B$ $\theta$ components for GOES 5 and GOES 6 . The results are shown in Table 1 for GOES 5 and in Table 2 for GOES 6. Events are classified first by the increase/decrease in the $V$ component, and those sub groups were then classified according to the increase/decrease in the $H$ component. Likewise, the initial changes were examined by the increase/decrease in magnitude $B$ and were sub divided according to the change in the $\theta$ component.

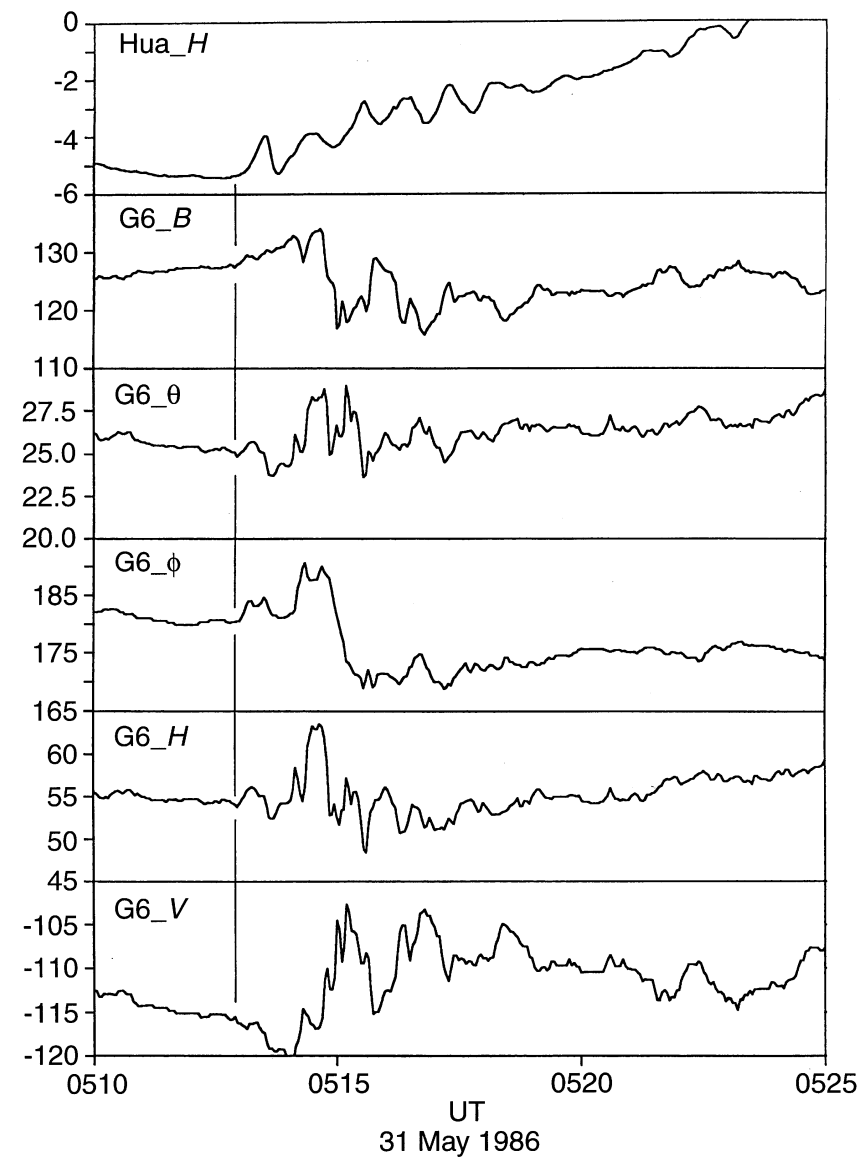

Fig 8. As Fig. 4, but for event 5 (31 May 1986)

General tendencies for the classification were that nearly $90 \%$ of the events showed an increase in the $V$ component or a decrease in the magnitude $B$. For the increased $V$ events, $52 \%(41 \%)$ were accompanied by a decrease (increase) in the $H$ component. Likewise, $63 \%$ of the decreased $B$ events were accompanied by an increase in the $\theta$ component.

According to the classifications in the tables, we could suggest that (1) there appeared no significant

Table 1. Classification of 32 GOES 5 events during 2100-0100 LT, $n=$ no. of events

\begin{tabular}{|c|c|c|c|}
\hline $\begin{array}{l}V \\
\text { increase }(n=29) \\
\text { decrease }(n=3)\end{array}$ & $\begin{array}{l}\text { increase }(n=12) \\
\text { increase }(n=1)\end{array}$ & $\begin{array}{l}H \\
\text { decrease }(n=15) \\
\text { decrease }(n=2)\end{array}$ & no change $(n=2)$ \\
\hline $\begin{array}{l}B \\
\text { decrease }(n=27) \\
\text { increase }(n=5)\end{array}$ & $\begin{array}{l}\text { increase }(n=17) \\
\text { increase }(n=2)\end{array}$ & $\begin{array}{l}\theta \theta \\
\text { decrease }(n=2) \\
\text { decrease }(n=2)\end{array}$ & $\begin{array}{l}\text { no change }(n=8) \\
\text { no change }(n=1)\end{array}$ \\
\hline
\end{tabular}

Table 2. Classification of 27 GOES 6 events during 2100-0100 LT

\begin{tabular}{llll}
\hline$V$ & & $H$ & no change $(n=3)$ \\
$\begin{array}{l}\text { increase }(n=24) \\
\text { decrease }(n=3)\end{array}$ & $\begin{array}{l}\text { increase }(n=10) \\
\text { increase }(n=2)\end{array}$ & $\begin{array}{l}\text { decrease }(n=11) \\
\text { decrease }(n=1)\end{array}$ & no change $(n=2)$ \\
\hline$B$ & increase $(n=16)$ & $\theta$ & no change $(n=1)$ \\
decrease $(n=22)$ & increase $(n=2)$ & decrease $(n=4)$ & $(n=2)$
\end{tabular}


differences in the distributions between two data sets from GOES 5 and GOES 6, irrespective of different satellite latitudes $\left(11^{\circ}\right.$ for GOES 5 and $9^{\circ}$ for GOES 6 in geomagnetic coordinates), (2) a significant number of events indicate an initial change as an increase in the $V$ component $(90 \%)$ and a decrease in the magnitude of $\mathrm{B}$ $(83 \%)$, (3) the polarity of the initial change appeared evenly for the $H$ component, (4) the $\theta$ component increased more often.

\section{Summary and discussion}

We have demonstrated that the initial field changes at geosynchronous altitudes occur nearly simultaneously with the Pi 2 onset at the dip-equator, and that their dominant changes were classified as an increase in the $V$ component or a decrease in the magnitude of $B$.

A simple interpretation of the initial field changes observed is to introduce a current system at the geosynchronous altitudes. If a dusk-to-dawn (eastward) current sheet is assumed, the latitudes of the current system would have been below the satellites, while if the dawn-to-dusk (westward) current sheet is assumed, the latitudes would be above the satellites. Irrespective of the latitudes of the current system, the current system might very often extend in the range of $L$ well inside the geosynchronous orbits, because the initial change of the $H$ component includes positive and negative polarities evenly.

Let us consider how the ground-satellite correlation observed at the initial change might be expected, taking account of the opposite change of magnitude $B$ between the geosynchronous altitudes and the dip-equator. Let us assume that the field disturbances were not confined in a narrow local time but expanded in the midnight sector for several hours of local time. Indeed, this assumption may not be unrealistic, because the region of the particle injections that occurred in association with the Pi 2 onset was reported to span $5 \mathrm{~h}$ of local time towards the morning sector (Saka et al., 1996c), and global and coherent oscillations were observed in the particle flux and in the magnetic fields both at the dipequator and the geosynchronous altitudes, irrespective of a large longitudinal separation (Saka et al., 1996b, 1997). Suppose that a global current system was set up at the $\mathrm{Pi} 2$ onset in the night-time magnetosphere as envisaged in the preceding. A spherical harmonic description of such global signals along geosynchronous orbit indicates that the main component affecting a radial dependence might be the $\mathrm{g}(2,1)$ term, which depends on $r^{1}$, where $r$ is a radial distance from the centre of the Earth (Mead, 1964). Taking account of the averaged amplitudes of $\mathrm{Pi} 2$ pulsations $(L=1)$ to be in the range of $1.16 \pm 0.50 \mathrm{nT}$ at the dip-equator, and those at the satellite altitudes $(L=6.6)$ in the range of $11.3 \pm 8.8 \mathrm{nT}$, the amplitude ratio estimated (1: $10.2 \pm 7.3)$ might be in accordance with this assumption. Of course, the $\mathrm{Pi} 2$ pulsations at the dip-equator may not be interpreted simply by the magnetic effect of the currents in the nightside magnetosphere. We would suggest that the first wave modes are excited from the current system suggested and propagated towards the Earth, causing azimuthal structure and cavity mode character at low-latitude stations (Allan et al., 1996; Takahashi et al., 1995).

If the primary cause of the Pi 2 pulsations at the dipequator can be regarded as a magnetic effect of the current system in the magnetosphere, it is likely that the dusk-to-dawn (eastward) current system is responsible for the observed initial changes at the geosynchronous altitudes, because the dawn-to-dusk (westward) current system may decrease the $H$ component at the dipequator at the Pi 2 onset, which did not occur.

In this report, we did not investigate the magnetic effect from the field-aligned current system. This current system may excite the transverse mode, and they could propagate along the field lines to the high latitudes. The wave signal may propagate thereafter to the lower latitudes, or form the current wedge system (Lester et al., 1983; Gelpi et al., 1987), which may have a potential effect for the Pi 2 wave form observed at the dipequator.

We have determined the manner of the initial change of the field lines at the geosynchronous altitudes which occurs at the Pi 2 onset. The field disturbances in space, as well as at the dip-equator last for some time thereafter, exceeding $15 \mathrm{~min}$, and they would take part in the formation of the substorm current system. For this reason, further studies are needed to investigate how the current system associated with these initial changes are related to and developed into the cross-tail currents of the substorm current wedge system.

Acknowledgements. The magnetometer observation at Huancayo was carried out as part of the Global Aurora Dynamics Campaign (see Oguti et al., 1988). We thank M. Ishitsuka and O. Veliz of Instituto Geofisico der Peru for their efforts in acquiring the magnetometer data at Huancayo. GOES magnetometer data are supplied by National Geophysical Data Center, NOAA.

Topical Editor K. H. Glaßmeier thanks P. Sutcliffe and another referee for their help in evaluating this paper.

\section{References}

Allan, W., F. W. Menk, B. J. Fraser, Y. Li, and S. P. White, Are low-latitude Pi 2 pulsations cavity/waveguide modes? Geophys. Res. Lett., 23, 765, 1996.

Baker, D. N., P. R. Higbie, E. W. Hones Jr., and R. D. Belian, High-resolution energetic particle measurements at $6.6 \mathrm{R}_{\mathrm{E}}, 3$. Low-energy electron anosotropies and short-term substorm predictions, J. Geophys. Res., 83, 4863, 1978.

Baumjohann, W., and K. Glaßmeier, The transient response mechanism and Pi 2 pulsations at substorm onset-review and outlook, Planet. Space Sci., 32, 1361, 1984.

Gelpi, C., H. J. Singer, and W. J. Hughes, A comparison of magnetic signatures and DMSP auroral images at substorm onset: three case studies, J. Geophys. Res., 92, 2447, 1987.

Jacobs, J. A., Geomagnetic micropulsation, Springer, Berlin, Heidelberg, New York, 1970.

Lanzerotti, L. J., and H. Fukunishi, Modes of hydromagnetic waves in the magnetosphere, Rev. Geophys., 12, 724, 1974.

Lester, M., W. J. Hughes, and H. J. Singer, Polarization patterns of Pi2 magnetic pulsations and the substorm current wedge, $J$. Geophys. Res., 88, 7958, 1983. 
McPherron, R. L., Substorm associated micropulsations at synchronous orbit, J. Geomagn, Geoelectr., 32, SII57, 1980.

Mead, G. D., Deformation of the geomagnetic field by the solar wind, J. Geophys. Res., 69, 1181,1964.

Oguti, T., T. Kitamura, and T. Watanabe, Global aurora dynamics campaign, 1985-1986 J. Geomagn. Geoelectr., 40, 485, 1988.

Orr, D., Magnetic pulsations within the magnetosphere: a review, J. Atmos. Terr. Phys., 35, 1, 1973.

Pashin, A. B., K. H. Glassmeier, W. Baumjohann, O. M. Raspopov, A. G. Yahnin, H. J. Opgenoorth, and R. J. Pellinen, $\mathrm{Pi} 2$ magnetic pulsations, aurora break-ups, and the substorm current wedge: a case study, J. Geophys., 51, 223, 1982.

Saito, T., Geomagnetic micropulsations, Space Sci. Rev., 10, 319, 1969.

Saka, O., O. Watanabe, M. Shinohara, H. Tachihara, and D. N. Baker, A comparison of the occurrence of very low latitude Pi 2 pulsations with magnetic-field and energetic-particle flux variations (30-300 keV) at geosynchronous altitudes, J. Geomagn. Geoelectr., 48, 1431, 1996a.

Saka, O., H. Akaki, O. Watanabe, and D. N.Baker, Groundsatellite correlation of low-latitude Pi 2 pulsations: a quasiperiodic field line oscillation in the magnetosphere, J. Geophys. Res, 101, 15433, 1996b.

Saka, O., O. Watanabe, and D. N. Baker, A possible driving source for transient field line oscillations in the post-midnight sector at geosynchronous altitudes, J. Geophys. Res., 101, 24719, 1996c.
Saka, O., K. Okada, O. Watanabe, D. N. Baker, G. D. Reeves, and R. D. Belian, Pi 2 associated particle flux and magnetic field modulations in geosynchronous altitudes, J. Geophys. Res., 102, $11363,1997$.

Sakurai, T., and R. L. McPherron, Satellite observations of Pi2 activity at synchronous orbit, J. Geophys. Res., 88, 7015, 1983.

Samson, J. C., and G. Rostoker, Polarization characteristics of Pi2 pulsations and implications for their source mechanisms: influence of the westward traveling surge, Planet. Space Sci., 31, 435, 1983.

Southwood, D. J., and F. W. Stuart, Pulsations at the substorm onset, in Dynamics of the magnetosphere, Eds. S.I.Akasofu, Reidel, Hingham, Mass., pp341, 1980.

Takahashi, K., S. Kokubun, T. Sakurai, R. W. McEntire, T. A. Potemra, and R. E. Lopez, AMPTE/CCE observations of substorm-associated standing Alfven waves in the midnight sector, Geophys. Res. Lett., 15, 1287, 1988.

Takahashi, K., S. Ohtani, and B. J. Anderson, Satistical analysis of Pi 2 pulsations observed by the AMPTE CCE spacecraft in the inner magnetosphere, J. Geophys. Res., 100, 21924, 1995.

Yeoman, T. K., M. P. Freeman, G. D. Reeves, M. Lester, and D. Orr, A comparison of midlatitude Pi2 pulsations and geostationary orbit particle injections as substorm indicators, $J$. Geophys. Res., 99, 4085, 1994. 